\title{
Accurate Maximum Power Tracking in Photovoltaic Systems Affected by Partial Shading
}

\author{
Pierluigi Guerriero, Fabio Di Napoli, Vincenzo d'Alessandro, and Santolo Daliento \\ Department of Electrical Engineering and Information Technology (DIETI), University of Naples Federico II, Via Claudio 21, \\ 80125 Naples, Italy \\ Correspondence should be addressed to Pierluigi Guerriero; pierluigi.guerriero@unina.it
}

Received 28 November 2014; Accepted 19 January 2015

Academic Editor: Ying Dai

Copyright ( 2015 Pierluigi Guerriero et al. This is an open access article distributed under the Creative Commons Attribution License, which permits unrestricted use, distribution, and reproduction in any medium, provided the original work is properly cited.

\begin{abstract}
A maximum power tracking algorithm exploiting operating point information gained on individual solar panels is presented. The proposed algorithm recognizes the presence of multiple local maxima in the power voltage curve of a shaded solar field and evaluates the coordinated of the absolute maximum. The effectiveness of the proposed approach is evidenced by means of circuit level simulation and experimental results. Experiments evidenced that, in comparison with a standard perturb and observe algorithm, we achieve faster convergence in normal operating conditions (when the solar field is uniformly illuminated) and we accurately locate the absolute maximum power point in partial shading conditions, thus avoiding the convergence on local maxima.
\end{abstract}

\section{Introduction}

In the last few years photovoltaic (PV) installations have become familiar in the landscape of our countries. Their diffusion was initially encouraged by even aggressive, apparently uneconomical, feed-in tariffs; nevertheless the merit of those policies is now fully appreciable and consists in the impressive prices fall for all components of a PV plant, so much so that less than $2 € / \mathrm{Wp}$ are now required as total investment. According to [1] such low prices led the cost of PV energy to be comparable with conventional energy sources and facilitated self-sustainment of the PV market. However, some limiting factors, which are inherently embedded in the PV technology, still persist. One of them is the large dependence on shadows, as they cause dramatic degradation of energy production. This issue prevents PV diffusion in the urban context where neighbor buildings can likely affect daily irradiance actually available on rooftop sites. The effect of shadowing is the deformation of the powervoltage curve exhibited by affected subfield. As will be shown in the next sections, indeed, the power-voltage $(P-V)$ curve of locally shaded strings (with the term string we indicate a group of series connected solar panels) is characterized by the presence of multiple local maxima; the consequence is that maximum power point tracking (MPPT) algorithms often stabilizes the PV system at an output power that is lower than the maximum achievable. This problem can be completely avoided by adopting distributed conversion schemes exploiting either microinverter [2-4] or solar panel optimizers [5-8]. Both of them lead each solar panel working at its own MPP; the drawback is that a complex power electronic circuit is brought on board solar panels, thus inducing a not negligible fault probability. As an alternative some centralized inverters allow a periodic scanning of the whole power-voltage curve which univocally individuates the absolute maximum on the curve; in this case a trade-off exists between the scan frequency and energy production because each time a scan is performed the system is driven far from the MPP; thus, when the string is uniformly irradiated the scan is definitively detrimental [9].

In this paper an approach that first identifies all maxima present in the power voltage curve and then drives the operating point of the solar system to the absolute maximum is described.

The procedure is based on the availability of a distributed sensor network devised to the measurement of the actual short circuit current $\left(I_{\mathrm{sc}}\right)$ and open circuit voltage $\left(V_{\mathrm{oc}}\right)$ for each panel forming the solar field. The algorithm for the 
tracking of the absolute maximum is based on the information achieved by the sensors; thus it is hereafter denoted as information based MPPT. The sensors allow on demand disconnection and by passing of solar panels from the string; electrical parameters are measured during the disconnection time (few milliseconds); thus they are not affected by the operating point of others solar panels belonging to the same string.

The paper is organized as follows. Section 2 reports the analytical model of the proposed approach. In Section 3 the distributed sensor network providing individual panels data is presented. In Section 4 numerical simulation results evidencing the effectiveness of the information based MPPT algorithm are reported. Section 5 shows experimental result concerning the comparison between the proposed approach and the behavior of a standard algorithm. Conclusions are drawn in Section 6.

\section{First-Order Algorithm}

The idea underlying the proposed MPPT algorithm assumes that it is possible to reconstruct an approximate version of the actual current-voltage ( $I-V)$ curve of a partially shaded string, formed by $N$ series connected solar panels, once the couple $I_{\mathrm{sc}}$ and $V_{\mathrm{oc}}$ is known for each panel. The algorithm estimates the voltage corresponding to the absolute maximum power point $\left(V_{\mathrm{MPP}}\right)$ and set this value as starting point for a standard perturb and observe $(\mathrm{P} \& \mathrm{O})$ tracking procedure $[10-$ 13]. Reconstruction of the string $I-V$ curve is performed by superposing a simplified form of the single panels $I-V$ curves which are approximated by trapezoidal shapes. Namely, once both $V_{\mathrm{oc}}$ and $I_{\mathrm{sc}}$ of a given panel are known, the coordinates of the maximum power point are calculated according to the following relations:

$$
V_{\mathrm{MPP}}=k_{V} \cdot V_{\mathrm{oc}}, \quad I_{\mathrm{MPP}}=k_{I} \cdot I_{\mathrm{sc}},
$$

where the coefficients $k_{V}$ and $k_{I}$ are taken from panel datasheets. Then the trapezoidal $I-V$ curve of the solar panel is drawn as shown in Figure 1, where the actual $I-V$ curve is also reported for comparison. It is worth noting that a critical point of this procedure is the strong temperature dependence of aforementioned coefficients; this implies that the working temperature of each solar panel is needed; actually $k_{V}$ and $k_{I}$ depend (weakly) on the irradiance as well. Both issues will be discussed in detail shortly.

As an example of string characteristic reconstruction Figure 2 shows the hypothetical case where a string is formed by three solar panels, each of them, protected with one bypass power diode, exhibiting a different short circuit current (i.e., they are subjected to different irradiation levels). In particular Figure 2(a) shows the "actual" $I-V$ and $P-V$ curves evaluated by means of standard circuit simulations assuming a one diode model for the solar panel [14]; as it was expected three local maxima are observable in the $P-V$ curve. Figure 2(b) reports the corresponding approximated curves; as can be seen all voltages corresponding to the maxima are almost coincident for the two cases.

The previous qualitative example can be easily generalized. Let us consider a string made by $N$ series connected

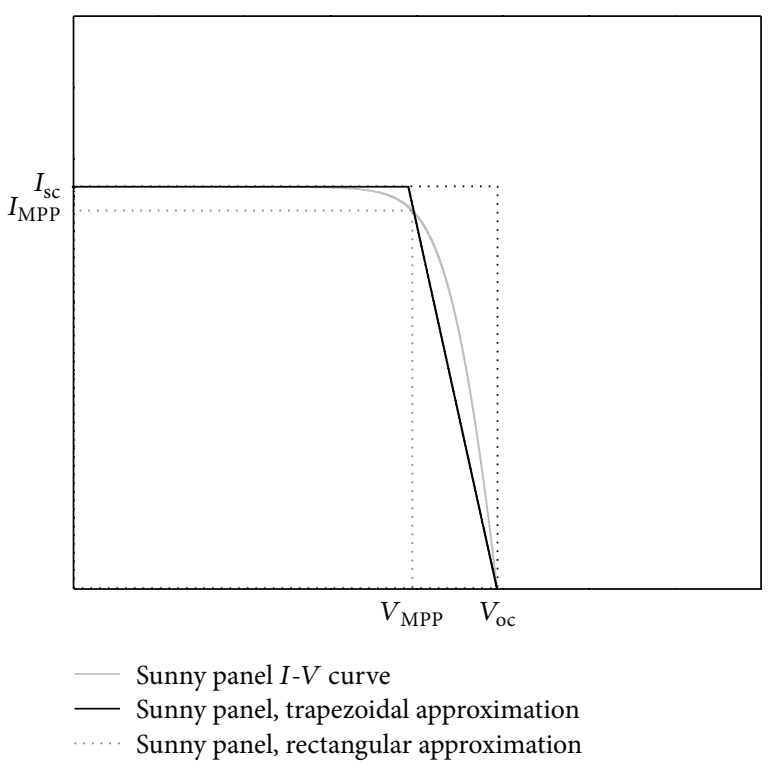

FIGURE 1: Current-voltage characteristic of a PV panel (solid grey line) compared to both rectangular (dotted black line) and trapezoidal (solid black line) approximation. $V_{\mathrm{MPP}}, I_{\mathrm{MPP}}, V_{\mathrm{oc}}$, and $I_{\mathrm{sc}}$ of the panel are also shown.

solar panels and assume that the string is subjected to $M$ different irradiance levels. It is important to note that the number of local maxima appearing in the $P-V$ curve coincides with the number of irradiance levels; thus we expect the presence of $M$ local maxima. In other words, each group of panels exhibiting the same $I_{\mathrm{sc}}$ contributes to the same local maximum. The voltage $V_{\mathrm{MPP}, j}$, corresponding to the $j$ th local MPP, can be computed as follows:

$$
V_{\mathrm{MPP}, j}=\sum_{k=1}^{M}\left(k_{v, k} \cdot V_{\mathrm{oc}, k} \cdot n_{k}\right) \cdot c_{j, k} \text {, }
$$

where $V_{\text {oc }, k}$ is the open-circuit voltage exhibited by all panels belonging to group $k$, which is defined as the panel group sharing the $j$ th irradiance level, $n_{k}$ is the number of panels forming group $k$, and $c_{j, k}$ is defined as follows:

$$
c_{j, k}= \begin{cases}1 & \text { when } I_{\mathrm{sc}, k} \geq I_{\mathrm{sc}, j} \\ 0 & \text { when } I_{\mathrm{sc}, k}<I_{\mathrm{sc}, j}\end{cases}
$$

Equations (2) and (3) can be interpreted by referring again to the simplified case shown in Figure 2. Let us evaluate, for example, the voltage $V_{\mathrm{MPP} 2}$ of the second maximum. As can be seen $V_{\text {MPP2 }}$ is almost equal to the sum of the voltages corresponding to the MPP of the first two panels because the third panel is bypassed. This condition is taken into account in (3) by setting $c_{j, 3}=0$; indeed, the fact that the short circuit current $I_{\mathrm{sc}, 3}$ of the third panel is lower than the others means that the third panel is bypassed.

Equation (2), however, does not account for the voltage drop across conducting bypass diodes $[15,16]$. In the previous example, indeed, the actual $V_{\mathrm{MPP} 2}$ is lower than the one given by (2) because the voltage drop across panel 3, coinciding 


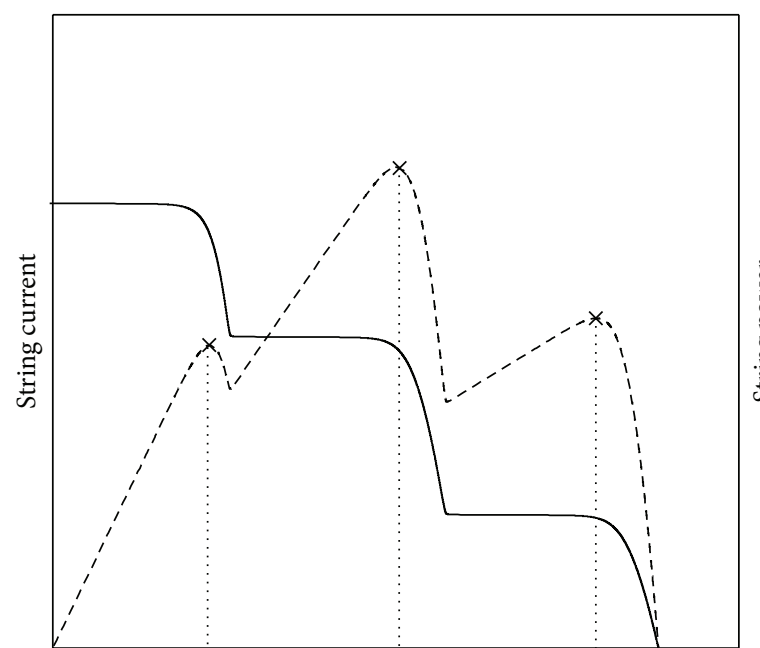

String voltage

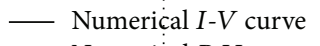

$\times$ Local maxima

- - Numerical $P$ - $V$ curve

(a)

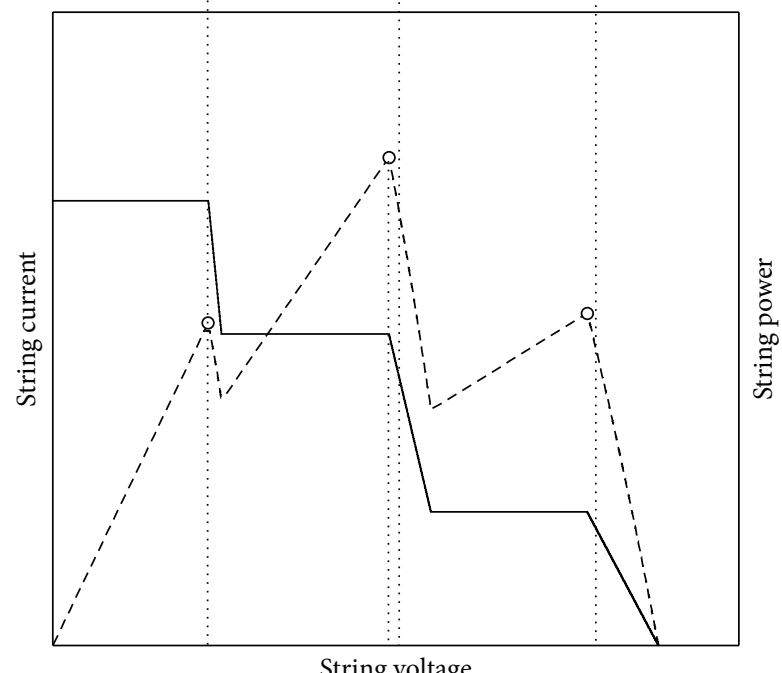

String voltage

- Trapezoidal approximated $I-V$ curve

- - - Trapezoidal approximated $I-V$ curve

(b)

Figure 2: (a) Simulated $I-V$ (solid line) and $P-V$ (dashed line) curve. (b) Trapezoidal approximation of both $I-V$ (solid line) and $P-V$ (dashed line) curve. Cycles indicate the local maxima.

with the forward voltage across the conducting bypass diode (about $0.7 \mathrm{~V}$ ), must be considered. Thus a more detailed model for $V_{\mathrm{MPP}, j}$ is

$$
V_{\mathrm{MPP}, j}=\sum_{k=1}^{M}\left(k_{v, k} \cdot V_{\mathrm{oc}, k} \cdot n_{k}\right) \cdot c_{j, k}-V_{D} \cdot \sum_{k=1}^{M} n_{k} \cdot \bar{c}_{j, k}
$$

where $V_{D}$ is the forward voltage drop of bypass diodes. Equation (4) simply states that all modules that do not contribute to $V_{\mathrm{MPP}, j}$ with their $V_{\mathrm{oc}}$ negatively affect $V_{\mathrm{MPP}, j}$ with their $V_{D}$.

Above equations can be conveniently expressed, for computational purposes, in a matrix form as follows:

$$
\mathbf{V}_{\mathrm{MPP}}=\mathbf{C} \cdot\left[\begin{array}{c}
n_{1} \cdot V_{\mathrm{oc}, 1} \\
\vdots \\
n_{M} \cdot V_{\mathrm{oc}, M}
\end{array}\right]-D \cdot \overline{\mathbf{C}} \cdot\left[\begin{array}{c}
n_{1} \cdot V_{D, 1} \\
\vdots \\
n_{M} \cdot V_{D, M}
\end{array}\right],
$$

where $\mathbf{C}, \overline{\mathbf{C}}$ are $M$-by- $M$ matrices defined according to (3).

With the aim to evaluate the power corresponding to each $V_{\mathrm{MPP}, j}$ the respective current $I_{\mathrm{MPP}, J}$ is also needed. The $j$ th $I_{\mathrm{MPP}}$ can be straightforward written as

$$
I_{\mathrm{MPP}, j}=k_{I, j} \cdot I_{\mathrm{sc}, j}
$$

so that the power values of the maxima are expressed in a matrix form as

$$
\mathbf{P}_{\mathrm{MPP}}=\mathbf{V}_{\mathrm{MPP}}^{T} \cdot \mathbf{I}_{\mathrm{MPP}},
$$

where $\mathbf{I}_{\mathrm{MPP}}$ is a $M$-by- $M$ matrix defined by

$$
I_{\mathrm{MPP}, j, k}= \begin{cases}k_{I, j} \cdot I_{\mathrm{sc}, j} & \text { when } j=k, \\ 0 & \text { otherwise. }\end{cases}
$$

The coefficients $k_{I}$ and $k_{V}$ depend on temperature and irradiance; they can be analytically determined as a function of both the open circuit voltage and the short circuit current as follows.

Let us consider the standard equation for a solar panel formed by $Z$ series connected solar cells

$$
I=I_{\mathrm{ph}}-I_{0}\left[\exp \left(\frac{V / Z}{n V_{T}}\right)-1\right] .
$$

By multiplying both members of (9) by the voltage $V$ the power $P$ supplied by the solar cell is achieved:

$$
P=V \cdot I=V I_{\mathrm{ph}}-V I_{0}\left[\exp \left(\frac{V / Z}{n V_{T}}\right)-1\right] .
$$

By definition $V_{\text {MPP }}$ is the voltage where (10) keeps its maximum; thus it can be calculated by deriving (10):

$$
I_{\mathrm{ph}}-I_{0}\left[\exp \left(\frac{V_{\mathrm{MPP}}}{n V_{T}}\right)-1\right]-\frac{V_{\mathrm{MPP}}}{n V_{T}} I_{0} \exp \left(\frac{V_{\mathrm{MPP}}}{n V_{T}}\right)=0 ;
$$

this derivative must be zero when $V=V_{\mathrm{MPP}}$ :

$$
\frac{\partial P}{\partial V}=I_{\mathrm{ph}}-I_{0}\left[\exp \left(\frac{V / Z}{n V_{T}}\right)-1\right]-\frac{V / Z}{n V_{T}} I_{0} \exp \left(\frac{V / Z}{n V_{T}}\right) .
$$

By neglecting 1 in the square brackets (12) can be rewritten as

$$
\left(1+\frac{V_{\mathrm{MPP}}}{n V_{T}}\right) \exp \left(\frac{V_{\mathrm{MPP}}}{n V_{T}}\right) \approx \frac{I_{\mathrm{ph}}}{I_{0}}
$$




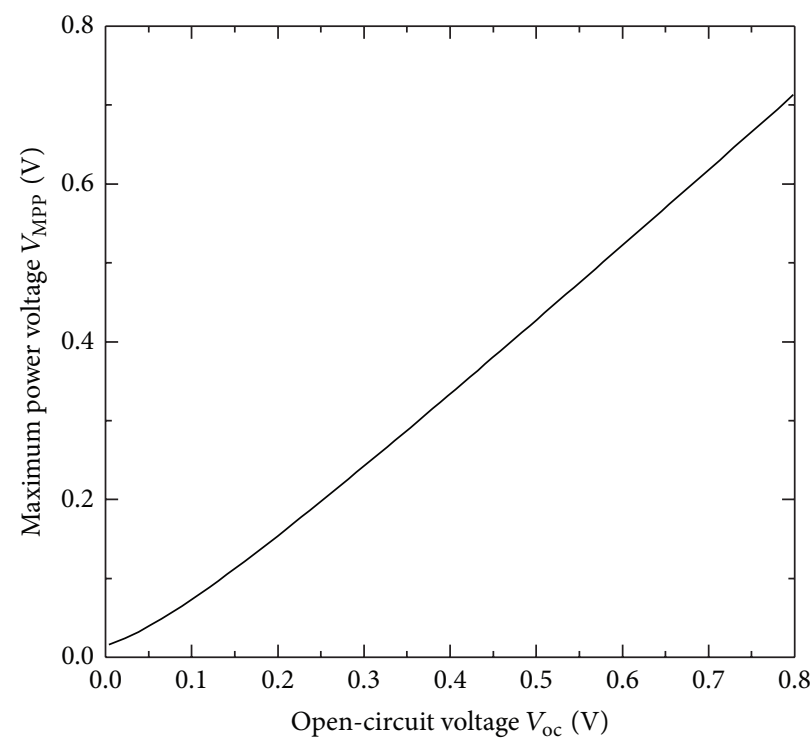

(a)

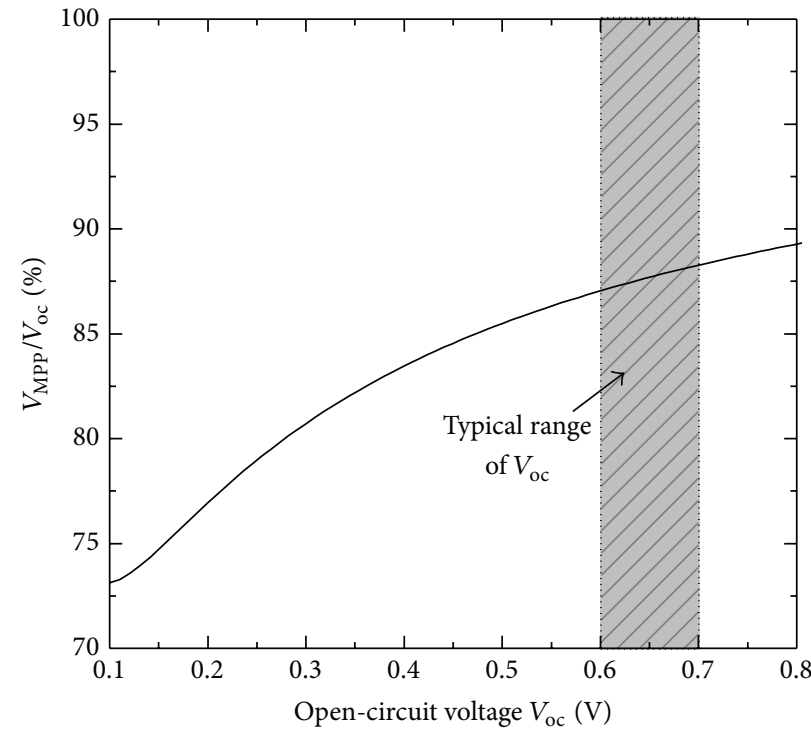

(b)

FIGURE 3: (a) MPP voltage against open-circuit voltage and (b) the percentage of $V_{\text {MPP }}$ with respect to the $V_{\text {oc }}$. The grey area highlights the typical $V_{\text {oc }}$ range.

Equation (13) can be further simplified by considering that $V_{\mathrm{MPP}} / n V_{T} \gg 1$ as

$$
\frac{V_{\mathrm{MPP}}}{n V_{T}} \exp \left(\frac{V_{\mathrm{MPP}}}{n V_{T}}\right) \approx \frac{I_{\mathrm{ph}}}{I_{0}} .
$$

By applying the logarithm to both sides, (14) becomes

$$
\begin{aligned}
n V_{T} \ln \left[\frac{V_{\mathrm{MPP}}}{n V_{T}} \exp \left(\frac{V_{\mathrm{MPP}}}{n V_{T}}\right)\right] & =n V_{T} \ln \left(\frac{V_{\mathrm{MPP}}}{n V_{T}}\right)+V_{\mathrm{MPP}} \\
& =n V_{T} \ln \left(\frac{I_{\mathrm{ph}}}{I_{0}}\right) .
\end{aligned}
$$

In (15) we recognize the standard expression of the open circuit voltage $V_{\text {oc }}$

$$
V_{\mathrm{oc}}=n V_{T} \ln \left(\frac{I_{\mathrm{ph}}}{I_{\mathrm{o}}}+1\right) \approx n V_{T} \ln \left(\frac{I_{\mathrm{ph}}}{I_{0}}\right),
$$

which allows the desired relation between $V_{\text {oc }}$ and $V_{\text {MPP }}$ where the dependence on temperature is shown:

$$
n \frac{k T}{q} \ln \left(\frac{q V_{\mathrm{MPP}}}{n k T}\right)+V_{\mathrm{MPP}}=V_{\mathrm{oc}} .
$$

Equation (17) is graphically represented in Figure 3.

It is interesting to note that in the typical operating range for $V_{\text {oc }}(0.6 \mathrm{~V}-0.7 \mathrm{~V}) V_{\mathrm{MPP}}$ is a fraction almost constant of $V_{\mathrm{oc}}$; from the measurement of $V_{\mathrm{oc}}$ a reliable estimation of $V_{\mathrm{MPP}}$ can be achieved.

A similar procedure can be adopted to obtain $I_{\mathrm{MPP}}$ as a function of $I_{\mathrm{sc}}$.
By neglecting 1 in (9) we can write

$$
V=n V_{T} \ln \left(\frac{I_{\mathrm{sc}}-I}{I_{0}}\right)
$$

hence

$$
\begin{gathered}
P=V \cdot I=I \cdot n V_{T} \ln \left(\frac{I_{\mathrm{sc}}-I}{I_{0}}\right), \\
\frac{\partial P}{\partial I}=n V_{T}\left[\ln \left(\frac{I_{\mathrm{sc}}-I}{I_{0}}\right)-\frac{I}{I_{\mathrm{sc}}-I}\right],
\end{gathered}
$$

that, is zero when $I=I_{\mathrm{MPP}}$. Consider

$$
\ln \left(\frac{I_{\mathrm{sc}}-I_{\mathrm{MPP}}}{I_{0}}\right)-\frac{I_{\mathrm{MPP}}}{I_{\mathrm{sc}}-I_{\mathrm{MPP}}}=0,
$$

which is the required relation between $I_{\mathrm{MPP}}$ and $I_{\mathrm{sc}}$. By numerically solving (20) the current at the MPP can be calculated from the measurement of $I_{\text {sc }}$.

In our approach the measurement of $V_{\mathrm{oc}}$ and $I_{\mathrm{sc}}$ is also exploited to gain the operating temperature of the solar panel and the irradiance. As it is well known, indeed, the short circuit current is a linear function of the irradiance while $V_{\mathrm{oc}}$ is an almost linear function (decreasing) of the temperature [17]. Respective coefficients are given in the data sheets accompanying the solar panels; hence the comparison of measured data with nominal values of $I_{\mathrm{sc}}$ and $V_{\mathrm{oc}}$ allows straightforward evaluation of actual illumination and temperature conditions.

\section{The Disconnection Circuit}

The algorithm discussed above requires the measurement of both $V_{\mathrm{oc}}$ and $I_{\mathrm{sc}}$. These values are usually not accessible 


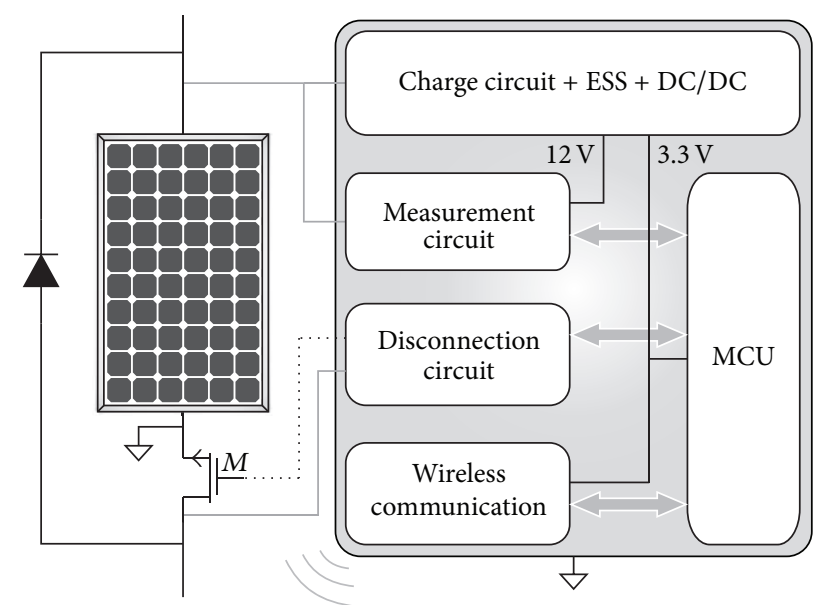

FIGURE 4: Schematic block diagram of the disconnection circuit.

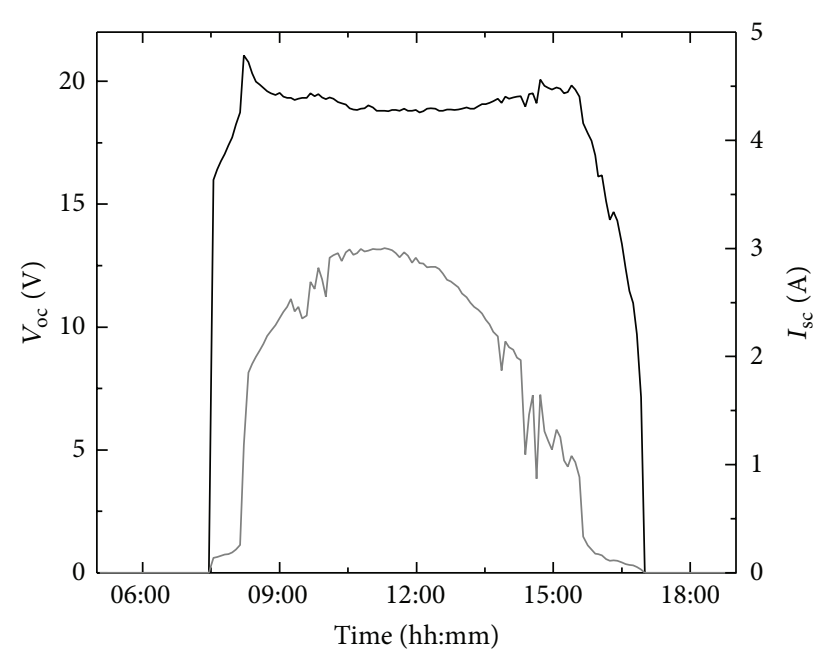

FIGURE 5: Individual panel short-circuit current (grey solid line) and open-circuit voltage (black solid line) against the time during the whole day.

in series connected solar panel. In our system we exploit a devised electronic circuit which temporary (few milliseconds) disconnects each solar panel from the string, performs the measurements of own panel parameters, and transmits measured data via wireless communication. The system is schematically represented in Figure 4.

As can be seen the disconnecting element is a power MOSFET which is series connected to the panel. When a measurement command is sent by the central coordinator the MOSFET is set in the OFF state and the solar panel behave as an isolated one. During the time that the panel is disconnected all parameters that are measured by the measurement unit are not affected by the operating point of the remaining string; hence the actual values of $I_{\mathrm{sc}}$ and $V_{\mathrm{oc}} \mathrm{can}$ be measured. It is worth noting that during the disconnection time the string current is not interrupted thanks to the additional bypass diode which gives a free path for the string current. Just as an example Figure 5 shows an over day $V_{\text {oc }}$ and $I_{\mathrm{sc}}$ collection for a solar panel embedded in a ten-panel string.

A network controller (named PV Unit) collects individual panel operating parameters (open-circuit voltage, shortcircuit current) measured by the distributed sensor network $[18,19]$. The first stage of the information based MPPT controller receives panels data from the PV Unit and estimates the voltage $\left(V_{\text {ref, },}\right)$ corresponding to the absolute maximum power point; then, the second stage, relying on an optimized perturb and observe $(\mathrm{P} \& \mathrm{O})$ approach $[10,12]$, tracks the actual MPP voltage.

\section{Numerical Simulations}

The performances of the algorithm were tested by means of circuit level numerical simulations performed in the PSpice environment. A solar string formed by ten $50 \mathrm{Wp}$ solar panels was designed. For reliable simulations each solar panel was divided into two subpanels, each protected by a devised bypass diode. The parameters of the solar panels were taken from the datasheets of the model ET-solar ET-M54050 [20], the same used for the experiments described in the next section.

Figure 6 shows the results we achieved when the string was subjected to four different irradiation levels, so as to have four local maxima in the $P-V$ curve.

In the figure the crosses indicate the actual position of each maximum while circles indicate the position estimated by the tracking algorithm. As can be seen the match is almost perfect; hence, once the voltage corresponding to the absolute power maximum has been calculated the subsequent $\mathrm{P} \& \mathrm{O}$ algorithm can be effectively driven to track that maximum.

As it is well known the maximum power point shows a significant decrease when the temperature increases. This effect can be almost entirely attributed to the dependence on temperature of the open circuit voltage

$$
V_{\mathrm{oc}}=n V_{T} \ln \left(\frac{J_{\mathrm{sc}}}{J_{0}}\right),
$$

where the term $J_{0}$ is given by

$$
J_{0} \approx q \frac{D_{n}}{\sqrt{D_{n} \tau_{n}} \cdot N_{A}} n_{i}^{2}
$$

Thus, the key parameters affecting the temperature dependence of PV modules are the reverse saturation current of the p-n junction and recombination lifetime $\tau$. Direct measurement of these parameters for analytical determining the temperature dependence of the MPP is quite complicated [21-24]; thus, in order to verify that the direct measurement of single panel $V_{\mathrm{oc}}$ and $I_{\mathrm{sc}}$ always leads to a close estimation of the actual $V_{\mathrm{MPP}}$, independently of operating conditions, numerical simulations were performed in a wide range of temperature (between $10^{\circ} \mathrm{C}$ and $80^{\circ} \mathrm{C}$ ) and irradiance levels (715 different shading shapes obtained by shading up to 4 panels in the string with 4 different shading levels, corresponding to $100 \mathrm{~W} / \mathrm{m}^{2}, 200 \mathrm{~W} / \mathrm{m}^{2}, 300 \mathrm{~W} / \mathrm{m}^{2}, 500 \mathrm{~W} / \mathrm{m}^{2}$, and $\left.800 \mathrm{~W} / \mathrm{m}^{2}\right)$. Results were collected in plots like the one 


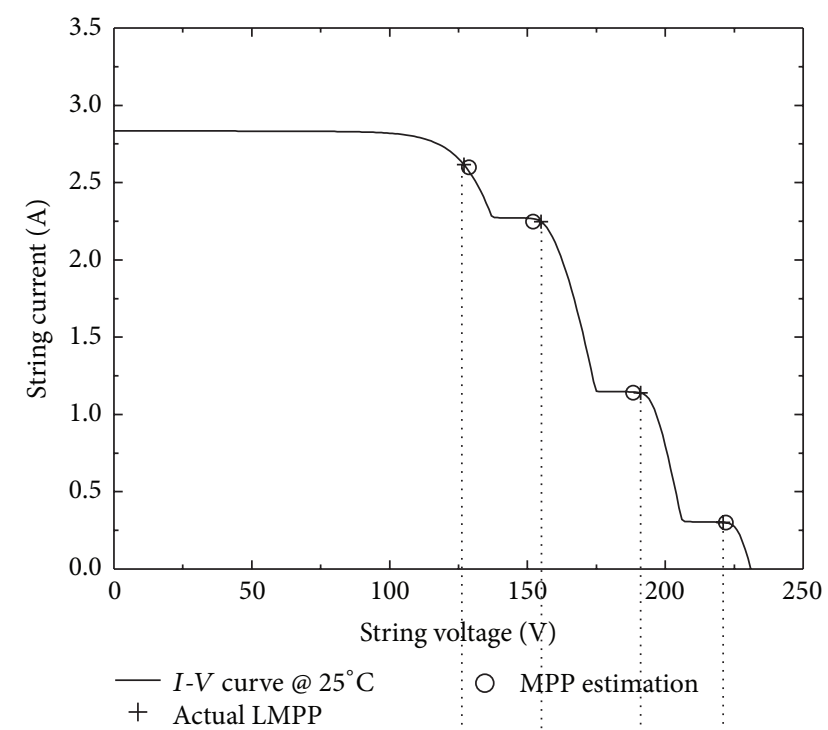

(a)

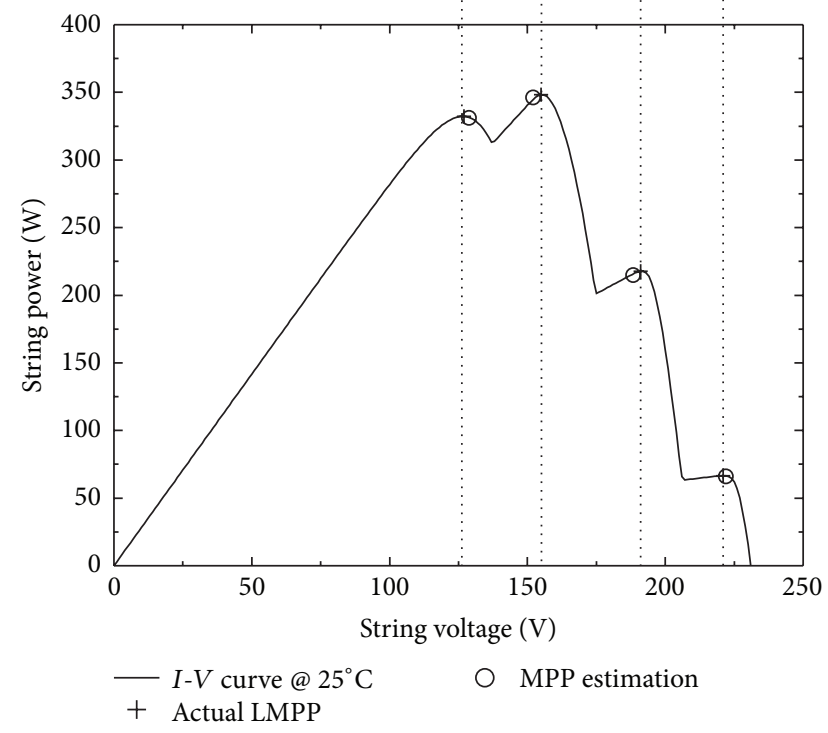

(b)

FIGURE 6: Current-voltage (a) and power-voltage (b) characteristics. The actual local maxima (crosses) and the maxima estimated by means of information based MPPT algorithm (circles) are also reported.

shown, as an example, in Figure 7. The figure depicts the relative voltage error in local maxima estimation corresponding to all the 715 shading cases at $T=25^{\circ} \mathrm{C}$.

The figure reports the percentage error on the estimation of $V_{\text {MPP }}$ as a function of the actual $V_{\text {MPP }}$ for all simulated cases. Two important comments can be made. First, the absolute error is always less than $2.5 \%$, which is a very small value. Second, the error is more likely an underestimation more than an overestimation. The results achieved at higher temperatures, which are likely reached during normal operation of solar panels, do not differ from Figure 7. They are summarized in Figure 8 where the percentage error of the $V_{\text {MPP }}$ estimation and the corresponding error bar are reported for each simulated temperature.

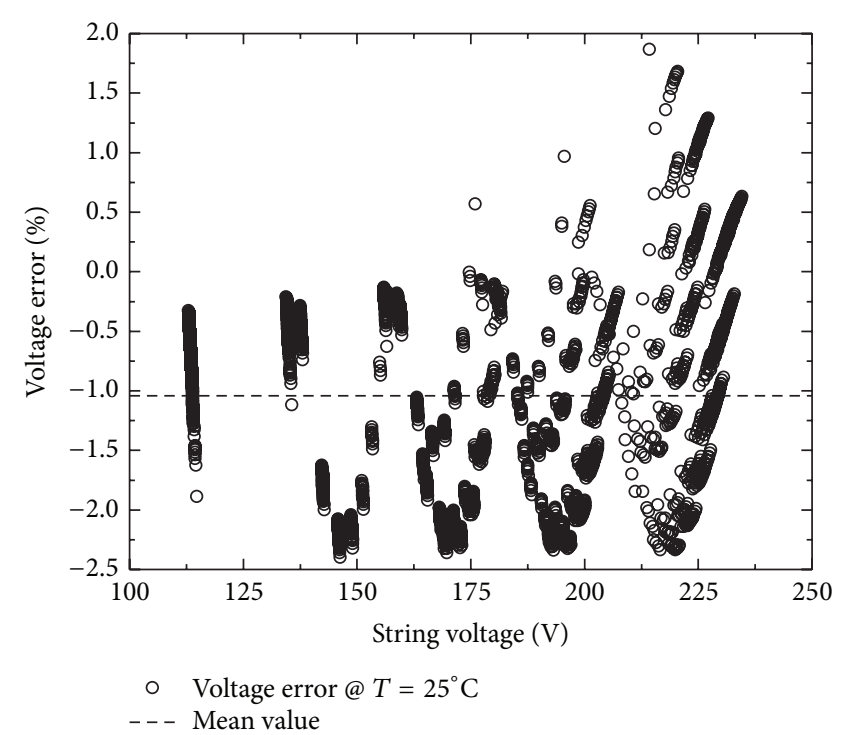

FIGURE 7: Relative voltage error in local maxima estimation. Cycles represents the estimation error with respect to the actual numerical result corresponding to all the 715 shading cases at $T=25^{\circ} \mathrm{C}$.

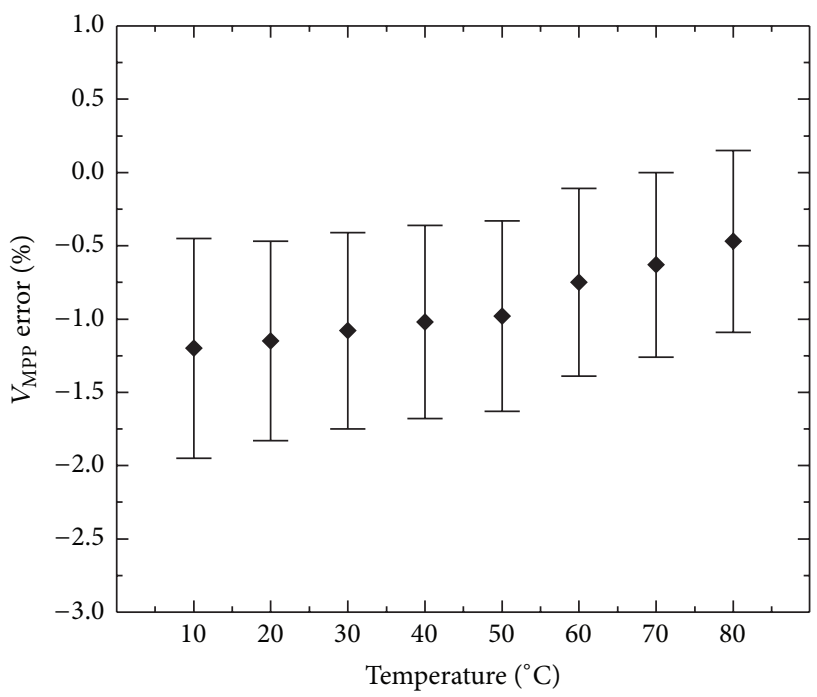

FIGURE 8: The percentage error on $V_{\mathrm{MPP}}$ estimation and the corresponding error bar for each considered temperature value.

\section{Experiments}

Experiments were conducted with the aim of both experimentally verifying the correct behavior of the whole system and comparing the proposed algorithm with the operation of a commercial inverter. Figure 9 shows the solar string exploited for the experiments.

It is composed by ten solar modules whose parameters were described in the previous section. As can be seen an uneven illumination frame was induced by covering some solar cells with semitransparent dyed sheets.

Two cases were considered. In the first case the string was kept under uniform illumination. The resulting $P$ - $V$ curve we measured is shown in Figure 10(a). 

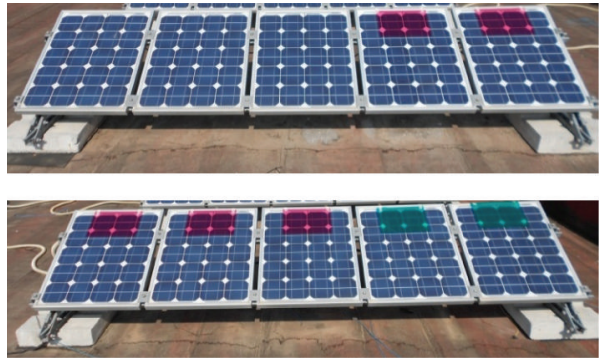

FIGURE 9: Ten-panel PV string. The desired shading profile is obtained superposing different kind of optical plastic film on selected PV panels.

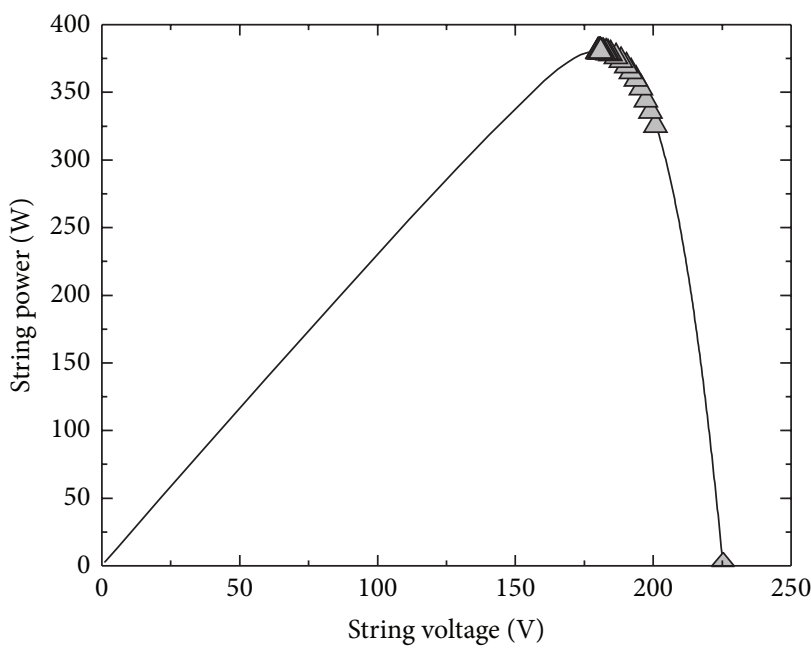

- P-V curve

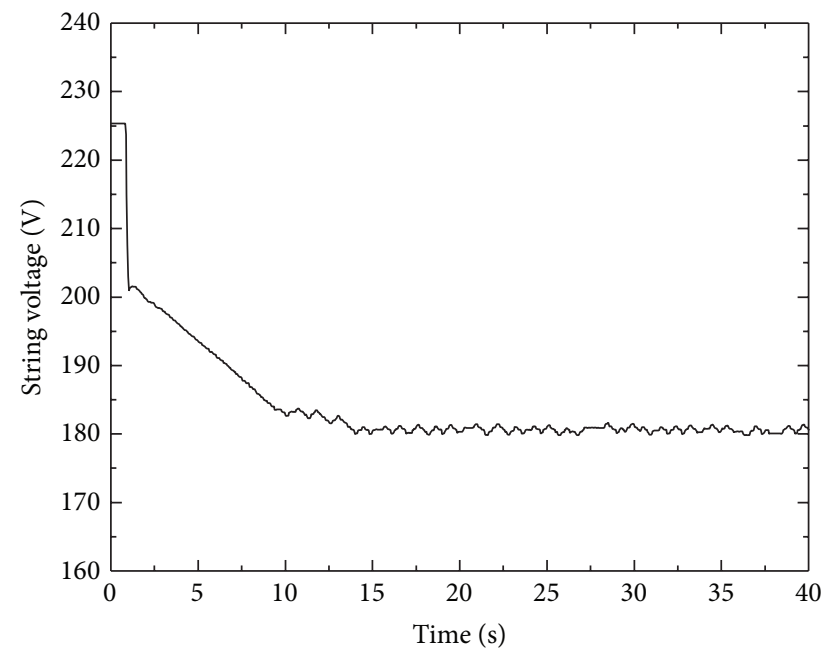

$\triangle$ Operating points

(a)

(b)

FIgURE 10: Sunny case. (a) Experimental power-voltage characteristic (solid line) of the 10-panel test string under full irradiation. The operating points of the string (triangles) by adopting a classic $\mathrm{P} \& \mathrm{O}$ algorithm are shown. (b) String power against the time.

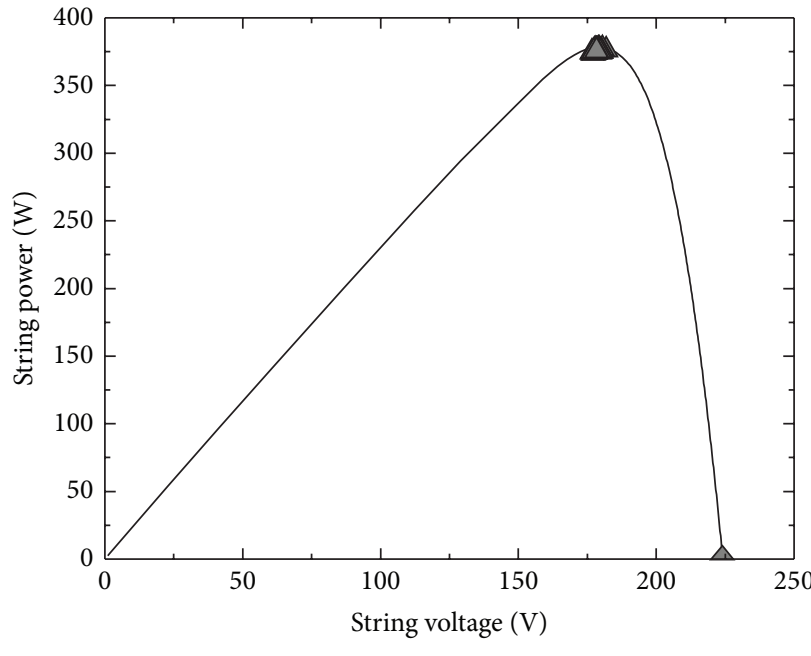

$\triangle$ Operating points

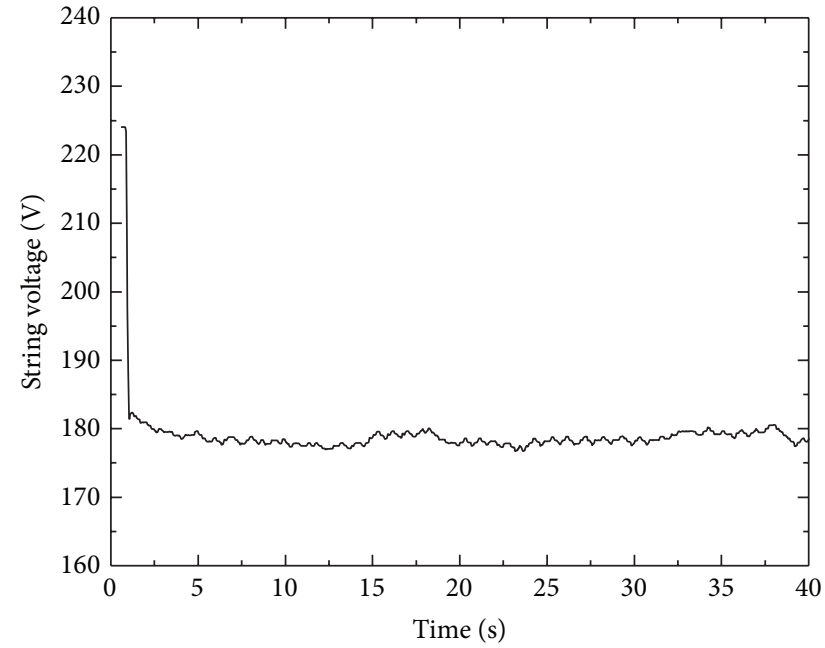

(a)

(b)

Figure 11: Sunny case. (a) Experimental power-voltage characteristic (solid line) of the 10-panel test string under full irradiation. The operating points of the string (triangles) by adopting the information based MPPT algorithm are shown. (b) String power against the time. 


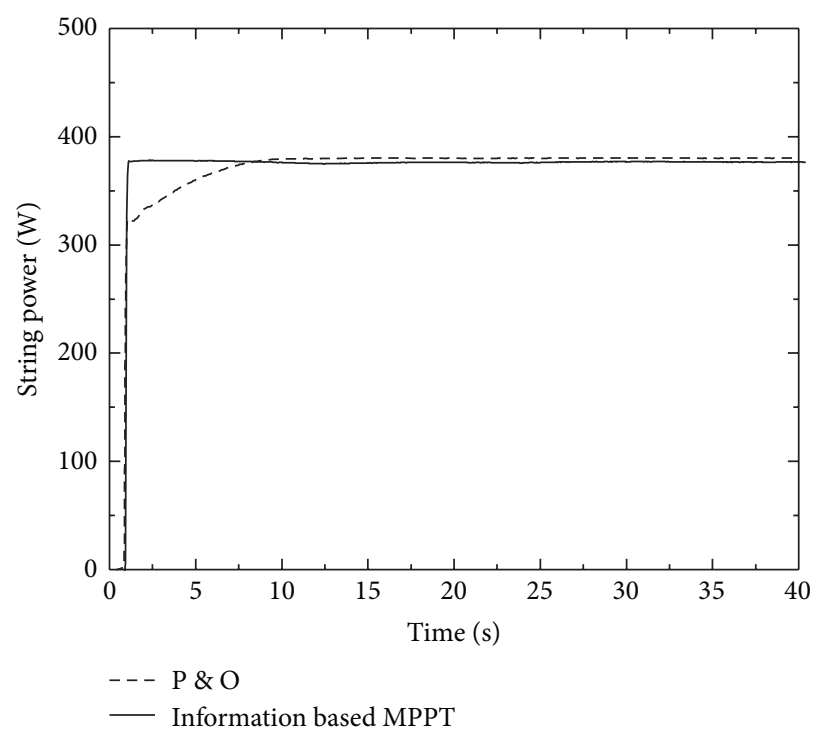

FIGURE 12: Comparison of string power behavior against the time corresponding to both P\&O (dashed line) and information based MPPT (solid line) algorithms.

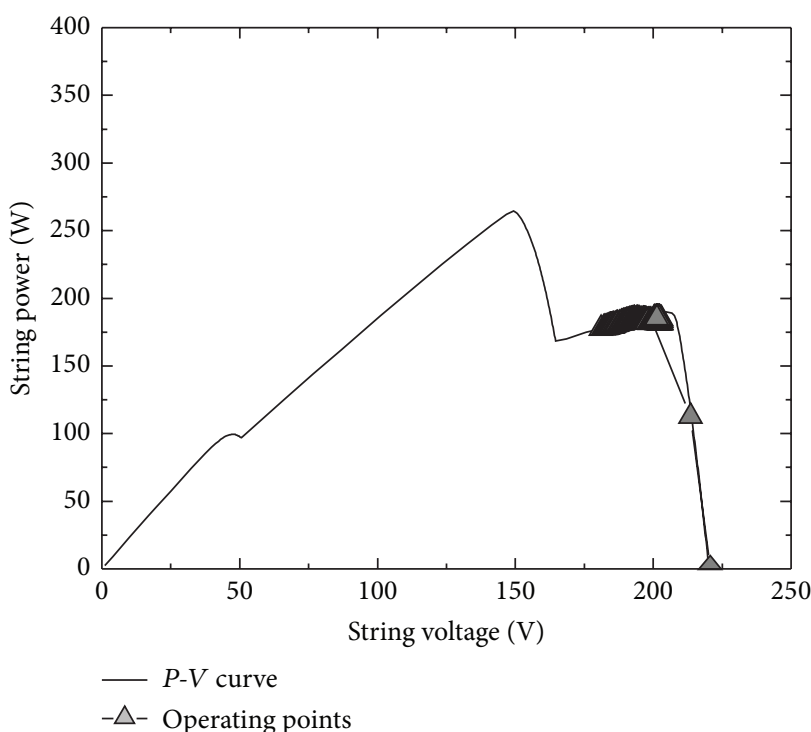

(a)

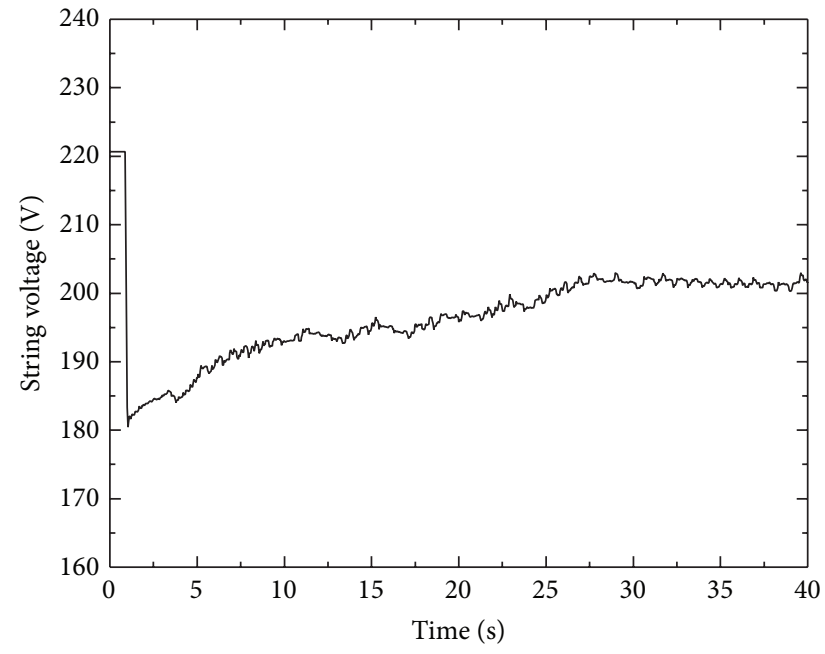

(b)

FIGURE 13: Partial-shading case. (a) Experimental power-voltage characteristic (solid line) of the 10-panel test string under partial-shading conditions. The operating points of the string (triangles) by adopting a classical $\mathrm{P} \& \mathrm{O}$ algorithm are shown. (b) String power against the time.

The evolution of the output voltage imposed by the tracking algorithm of the commercial inverter adopting a conventional P\&O algorithm is shown in Figure 10(b).

The algorithm assumes that the MPP lies at about $80 \%$ of $V_{\text {oc }}$; this value is assumed as starting point for the "hill climbing." At the end the operating point stabilizes at around $180 \mathrm{~V}$, that is, the actual voltage of the MPP.

Figure 11 shows the behavior of the tracking algorithm on the same $P-V$ curve.

In this case the starting voltage was estimated from the knowledge of $I_{\mathrm{sc}}$ and $V_{\mathrm{oc}}$ and $V_{\mathrm{MPP}}$ was immediately achieved. The two algorithms are compared in Figure 12 which reports the output power achieved by each of them when uniform illumination conditions are assumed.

As can be inferred the proposed information based MPPT keeps the MPP faster.

A more interesting case is the second one we considered, where illumination was not uniform, so as to have the $P-V$ curve shown in Figure 13(a).

Also in this case we compared the performances of the standard algorithm with the proposed one. Figure 13(b) shows the output voltage given by the standard one.

Again, the algorithm starts from $V_{\mathrm{oc}}$ and tries, as starting point, $80 \%$ of that value; then the voltage is increased to 


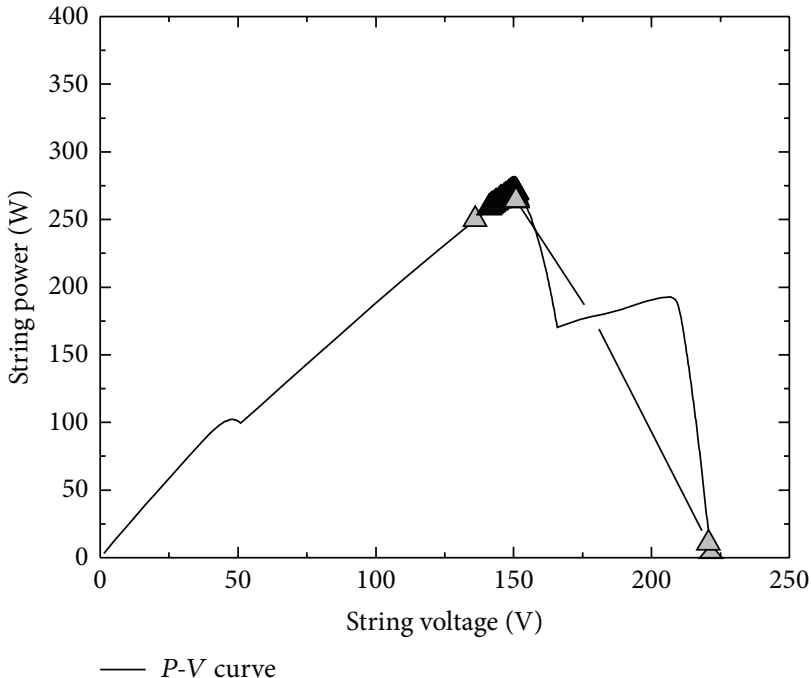

$-\triangle$ - Operating points

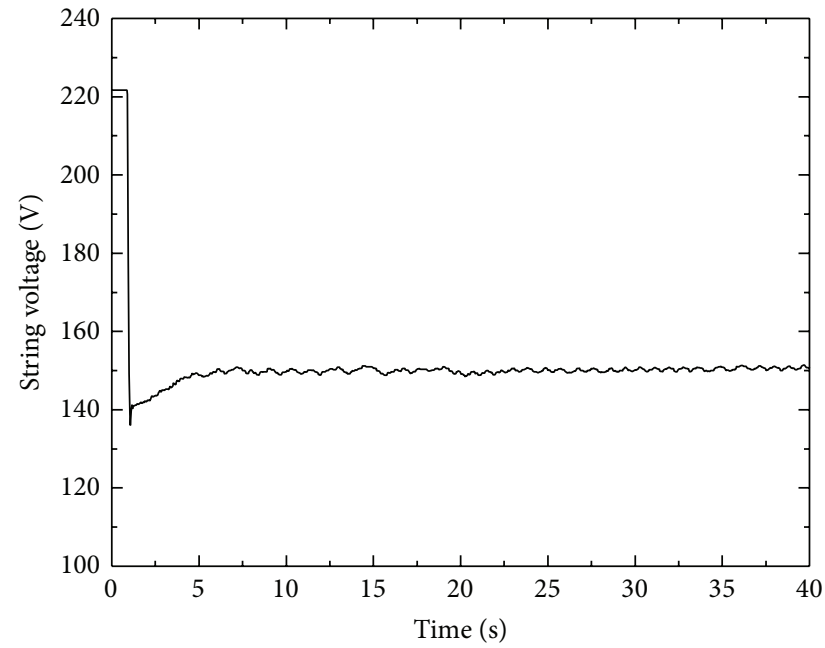

(a)

(b)

FIgURE 14: Partial-shading case. (a) Experimental power-voltage characteristic (solid line) of the 10-panel test string under partial-shading conditions. The operating points of the string (triangles) by adopting the information based MPPT algorithm are shown. (b) String power against the time.

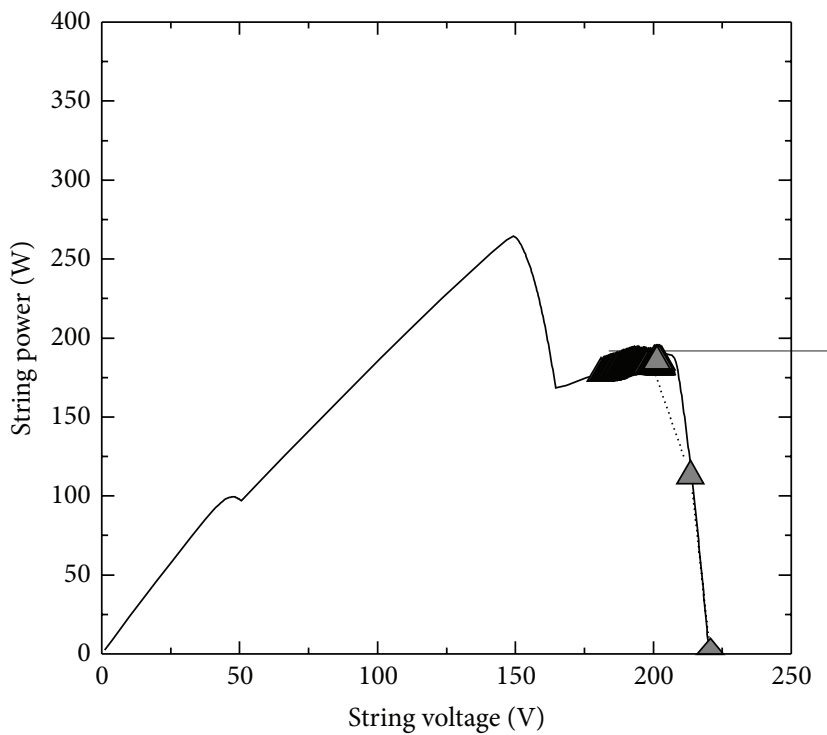

(a)

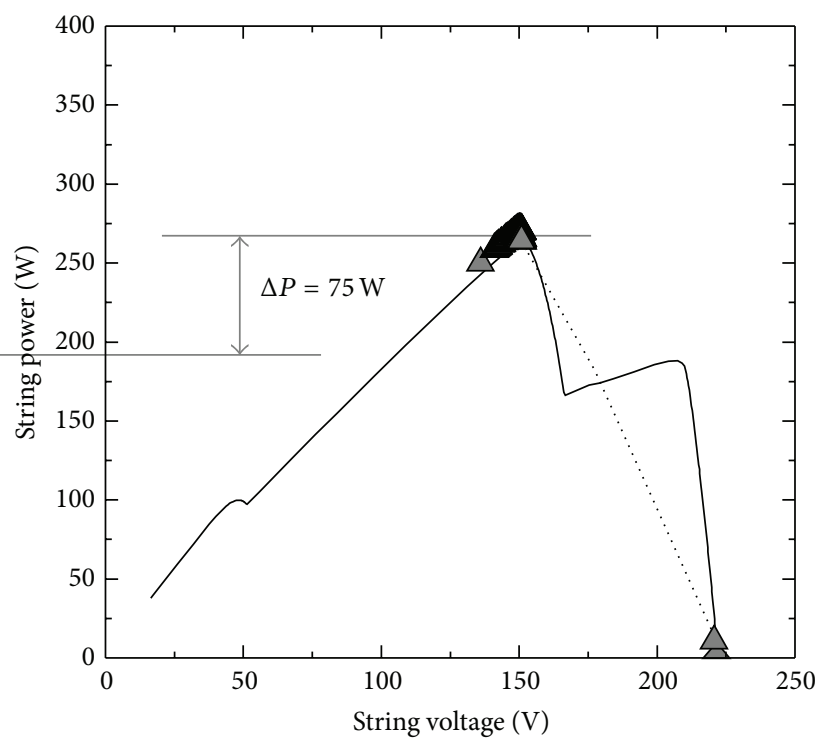

(b)

FIGURE 15: Algorithms comparison. The tracking performance corresponding to the commercial inverter (a) and the information based MPPT (b) are compared. The operating points (triangle) over the $P$ - $V$ curves (solid lines) are reported.

stabilize at about $200 \mathrm{~V}$. By comparing with the $P$ - $V$ curve we observe that the algorithm tracked the local maximum on the right side of the PV curve.

Figure 14 shows the operation of the information based MPPT.

In this case the starting point is a slight underestimation of the actual absolute maximum which is immediately reached by the system as shown in Figure 14(b).

Figure 15 shows the comparison performed on the above $P-V$ curves.
The most important observation is that the information based MPPT correctly recognizes the absolute maximum thus giving a power gain of about $75 \mathrm{~W}$ over the standard system.

\section{Conclusions}

Local information about the operation of each panel embedded in a PV string can strongly improve the overall efficiency of a PV system. In this paper an information based MPPT 
algorithm, exploiting the information provided by individual panel sensor network, has been presented.

Experiments comparing the operation of a standard $\mathrm{P} \& \mathrm{O}$ algorithm with the proposed approach demonstrate the capability of the present approach to locate the true MPP, thus avoiding power losses due to tracking failures. Moreover, a faster convergence has been reached with respect to a classic $\mathrm{P} \& \mathrm{O}$ algorithm.

\section{Conflict of Interests}

The authors declare that there is no conflict of interests regarding the publication of this paper.

\section{References}

[1] G. Masson, S. Orlandi, M. Rekinger et al., Global Market Outlook for Photovoltaics 2014-2018, European Photovoltaic Industry Association, 2014, http://www.epia.org/.

[2] D. Meneses, F. Blaabjerg, Ó. García, and J. A. Cobos, "Review and comparison of step-up transformerless topologies for photovoltaic AC-module application," IEEE Transactions on Power Electronics, vol. 28, no. 6, pp. 2649-2663, 2013.

[3] S. B. Kjaer, J. K. Pedersen, and F. Blaabjerg, "A review of singlephase grid-connected inverters for photovoltaic modules," IEEE Transactions on Industry Applications, vol. 41, no. 5, pp. 1292 1306, 2005.

[4] M. Coppola, S. Daliento, P. Guerriero, D. Lauria, and E. Napoli, "On the design and the control of a coupled-inductors boost dc-ac converter for an individual PV panel," in Proceedings of the 21st International Symposium on Power Electronics, Electrical Drives, Automation and Motion (SPEEDAM '12), pp. 1154-1159, June 2012.

[5] N. Femia, G. Lisi, G. Petrone, G. Spagnuolo, and M. Vitelli, "Distributed maximum power point tracking of photovoltaic arrays: novel approach and system analysis," IEEE Transactions on Industrial Electronics, vol. 55, no. 7, pp. 2610-2621, 2008.

[6] G. Petrone, G. Spagnuolo, and M. Vitelli, "An analog technique for distributed MPPT PV applications," IEEE Transactions on Industrial Electronics, vol. 59, no. 12, pp. 4713-4722, 2012.

[7] B. V. P. Chong and L. Zhang, "Controller design for integrated PV-converter modules under partial shading conditions," Solar Energy, vol. 92, pp. 123-138, 2013.

[8] S.-M. Chen, T.-J. Liang, and K.-R. Hu, "Design, analysis, and implementation of solar power optimizer for DC distribution system," IEEE Transactions on Power Electronics, vol. 28, no. 4, pp. 1764-1772, 2013.

[9] M. Boztepe, F. Guinjoan, G. Velasco-Quesada, S. Silvestre, A. Chouder, and E. Karatepe, "Global MPPT scheme for photovoltaic string inverters based on restricted voltage window search algorithm," IEEE Transactions on Industrial Electronics, vol. 61, no. 7, pp. 3302-3312, 2014.

[10] D. P. Hohm and M. E. Ropp, "Comparative study of maximum power point tracking algorithms," Progress in Photovoltaics: Research and Applications, vol. 11, no. 1, pp. 47-62, 2003.

[11] M. A. G. de Brito, L. Galotto, L. P. Sampaio, G. de Azevedo Melo, and C. A. Canesin, "Evaluation of the main MPPT techniques for photovoltaic applications," IEEE Transactions on Industrial Electronics, vol. 60, no. 3, pp. 1156-1167, 2013.

[12] K. Ishaque and Z. Salam, "A review of maximum power point tracking techniques of PV system for uniform insolation and partial shading condition," Renewable \& Sustainable Energy Reviews, vol. 19, pp. 475-488, 2013.

[13] N. Onat, "Recent developments in maximum power point tracking technologies for photovoltaic systems," International Journal of Photoenergy, vol. 2010, Article ID 245316, 11 pages, 2010.

[14] J. Cubas, S. Pindado, and A. Sanz-Andrés, "Accurate simulation of MPPT methods performance when applied to commercial photovoltaic panels," The Scientific World Journal. In press.

[15] V. D’Alessandro, P. Guerriero, and S. Daliento, "A simple bipolar transistor-based bypass approach for photovoltaic modules," IEEE Journal of Photovoltaics, vol. 4, no. 1, pp. 505-513, 2014.

[16] S. Daliento, L. Mele, P. Spirito, R. Carta, and L. Merlin, "Experimental study on power consumption in lifetime engineered power diodes," IEEE Transactions on Electron Devices, vol. 56, no. 11, pp. 2819-2824, 2009.

[17] S. Daliento, V. d'Alessandro, and P. Guerriero, Dispositivi e sistemi fotovoltaici, Edises, 2014.

[18] M. Gargiulo, P. Guerriero, S. Daliento et al., "A novel wireless self-powered microcontroller-based monitoring circuit for photovoltaic panels in grid-connected systems," in Proceedings of the International Symposium on Power Electronics, Electrical Drives, Automation and Motion (SPEEDAM '10), pp. 164-168, June 2010.

[19] P. Guerriero, V. d'Alessandro, L. Petrazzuoli, G. Vallone, and S. Daliento, "Effective real-time performance monitoring and diagnostics of individual panels in PV plants," in Proceedings of the 4th International Conference on Clean Electrical Power (ICCEP '13), pp. 14-19, June 2013.

[20] “Datasheet of ET-solar PV module ET-M54050", http://www .etsolar.com.ar/.

[21] S. Bellone, G. D. Licciardo, S. Daliento, and L. Mele, "Experimental measurements of majority and minority carrier lifetime profile in SI epilayers by the use of an improved OCVD method," IEEE Electron Device Letters, vol. 26, no. 7, pp. 501503, 2005.

[22] S. Daliento, A. Sanseverino, and P. Spirito, "An improved model for extraction of strongly spatial dependent lifetimes with the ac lifetime profiling technique," IEEE Transactions on Electron Devices, vol. 46, no. 8, pp. 1808-1810, 1999.

[23] S. Daliento, L. Mele, E. Bobeico, L. Lancellotti, and P. Morvillo, "Analytical modelling and minority current measurements for the determination of the emitter surface recombination velocity in silicon solar cells," Solar Energy Materials \& Solar Cells, vol. 91, no. 8, pp. 707-713, 2007.

[24] S. Daliento and L. Mele, "Approximate closed-form analytical solution for minority carrier transport in opaque heavily doped regions under illuminated conditions," IEEE Transactions on Electron Devices, vol. 53, no. 11, pp. 2837-2839, 2006. 

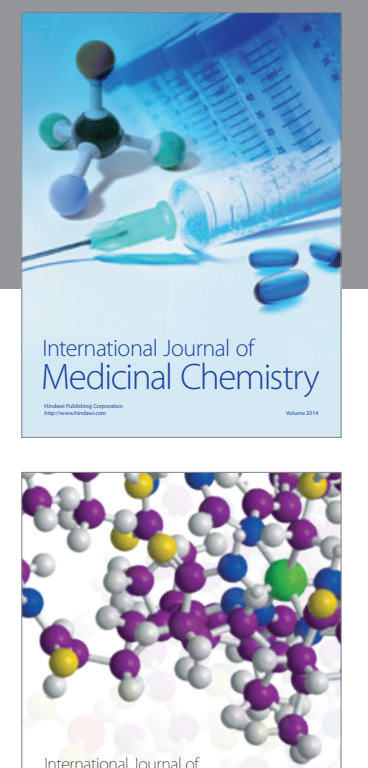

\section{Carbohydrate} Chemistry

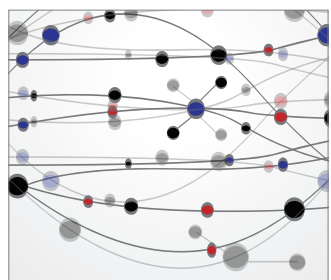

The Scientific World Journal
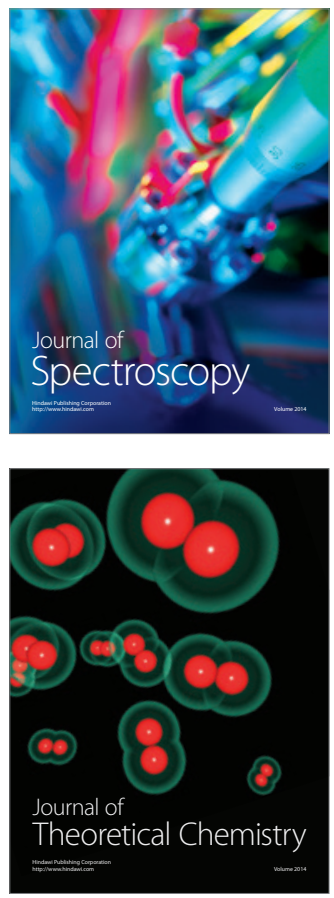
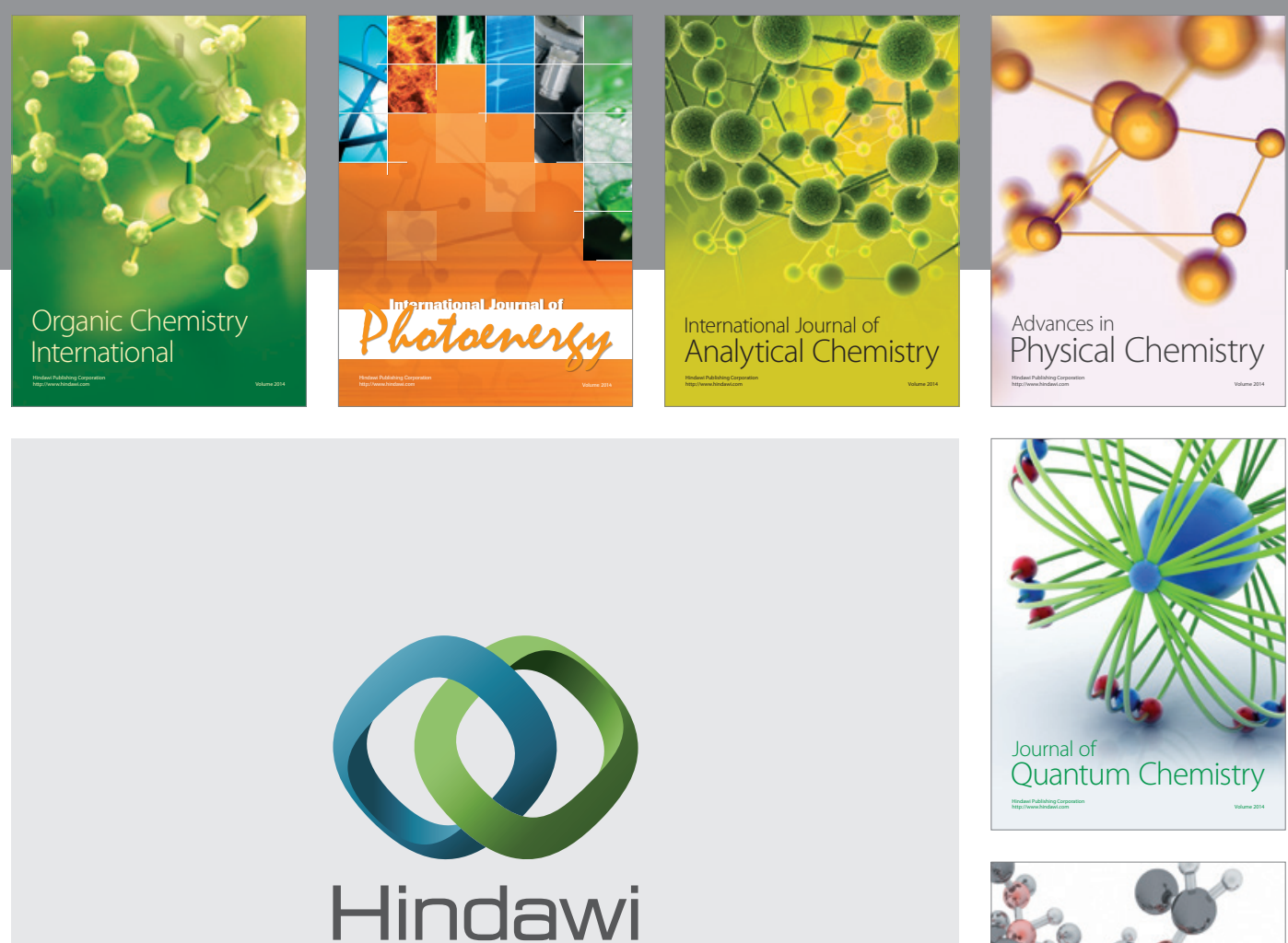

Submit your manuscripts at

http://www.hindawi.com

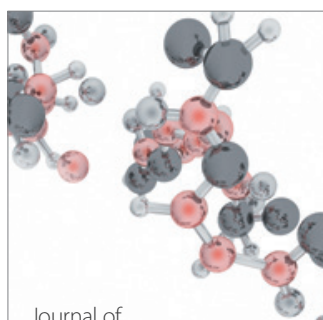

Analytical Methods

in Chemistry

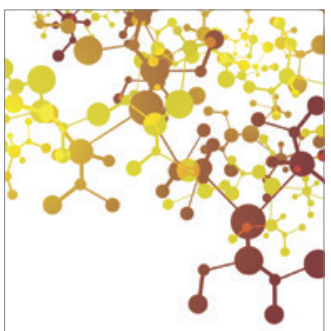

Journal of

Applied Chemistry

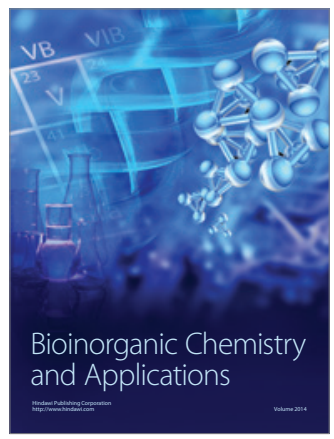

Inorganic Chemistry
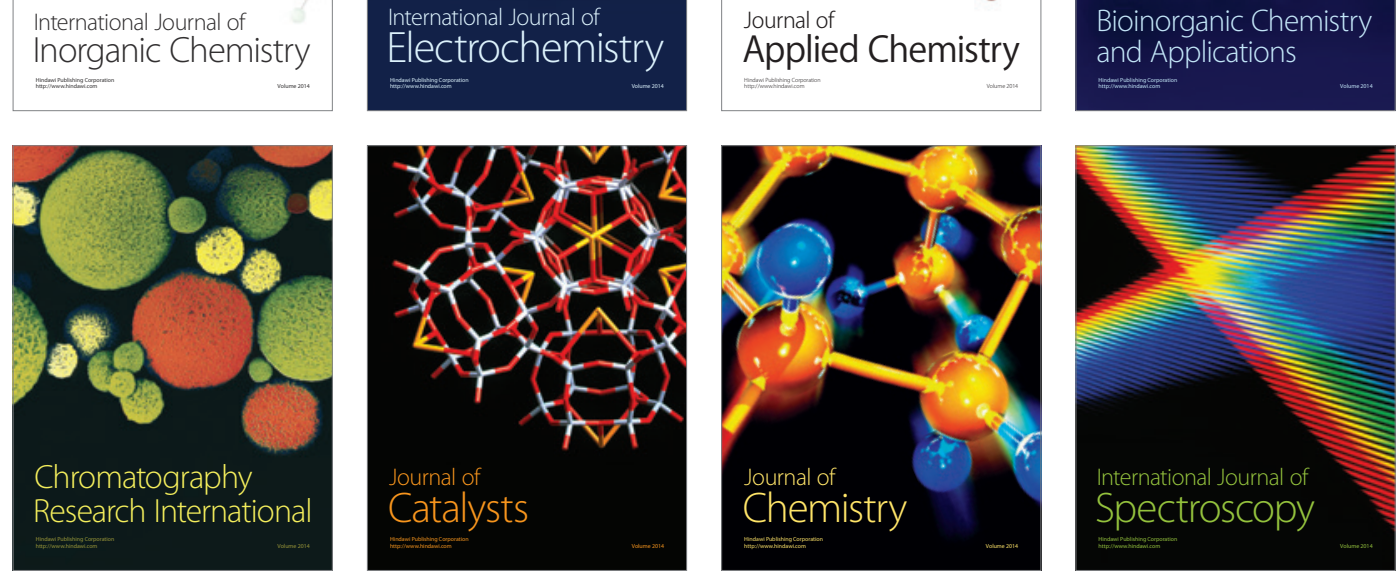